\title{
The Use of Verbal and Visual Metaphors in the Construction of Satire in Nigerian Political Cartoons
}

\author{
Ibrahim Sani, Umaru Musa Yar'aduwa, University Nigeria
}

\begin{abstract}
Given the increased use of political cartoons especially in Nigerian print media and the fact that political cartoons rely on satire constructed in graphic or visual illustrations to express their meanings, Political cartoons are viewed as a form of political satire (Townsend et al., 2008). Through these verbal and visual devices cartoonists construct meaningful and persuasive media messages reflecting current issues and scenarios that are related to social and political happenings in a society thereby contributing significantly to political debates and commentary (Conners, 2005). Using political cartoons published in Nigerian newspapers, this article explores how Nigerian cartoonists employ verbal and visual devices such as visual metaphor in the construction of satire to ridicule politicians and public officers as a means of persuading and influencing public opinion.It has been argued that visual metaphors must be regarded as visual projections and representations of metaphorical concepts. In respect of this, a cognitive perspective of metaphor and semiotic approach were applied to analyzethe cartoons visual presentations of real world events.This study suggests that visual metaphor is a creative and thought provoking rhetoric that strongly appeals to the minds of readers more succinctly than its verbal counterpart. The findings of the study indicate thatthe cartoons mostly indicate laughing satirical tones and the interplay between verbal and nonverbal devices in the political cartoon genre of media discourse provides a creative way of using language to accomplish specific communicative purposes in a society.Moreover, the findings suggest that visual metaphor can be utilized conceptually to construct satire as a way of denouncing social, political and economic vices to transforming societal values.
\end{abstract}

Keywords: Political cartoons, Nigerian Newspapers, Satire, Cognitive theory of metaphor,Rhetorical devices Visual metaphor 


\section{Introduction}

The aim of this article is to explore different ways in which metaphors are expressed visually to communicate social and political messages in newspaper cartoons. In order to demonstrate the central arguments, the analysis of cartoons from Nigerian daily newspapers will be presented. Cartoons are pictorial representations that employ visual rhetoric to convey messages that reflect what happen in the society. These messages are usually constructed in such a way that they identify images of individuals, group or events and describe them according to the ways they refer to real-world events (Elkins, 2003). Hence, metaphor is a natural language phenomenon that allows us to perceive abstract concepts and ideas through strong comparison by mapping such abstract ideas to concrete, real and existing ones. For this reason, our first argument suggests that metaphors are more concisely and precisely expressed visually in relation to their underlying metaphorical thoughts. For better understanding of visual metaphor, (See El Refaie, 2003). Thus, visual metaphors are pictorial versions of verbally expressed metaphorical way of thinking which is congruent with the main domains of cognitive metaphor theory.

The second argument is that by their by their nature, description and definitions, visual metaphors are highly context-dependent. Thus, a better understanding of visual metaphor is attained by studying them within the domain of their context which is mainly the socio-political arena in the case of political cartoons. This provides the audience with background knowledge which is a prerequisite for better analogical interpretation of the underlying metaphorical depictions.

Considering the fact that political cartoons make use of allusive references to individuals and group, visual metaphor could provide subtle means for identifying such references; because visual metaphors generally have much impact than verbal metaphorical expressions in terms of understanding the relayed media messages and their influenceon the audiences when used in appropriate and specific context. Generally, pictures say much at a glance about a particular thing or a message that 
thousand words cannot do. That is to say, cartoons depictions rely much on the visual images while depicting an individual or event. These visual devicesenable the audiences to make sense of the imaginative language incorporated in the visual commentary which consists of puns, word play, gags, jokes, stories and narratives. This creative use of visual forces to communicate important messages constitute a unique feature of the cartoon genre that plays the roleof a distinct and significant medium of communication.

This article contributes to literature by highlighting the use of verbal and visual metaphoric devices employed by cartoonists to create and convey satire as a communicative vehicle of persuading audiences on current socio-political issues especially in Nigerian media discourse. To achieve this, the political cartoons published in two most prominent and widely read newspapers in Nigeria, namely DailyTrust and Vanguard,were analyzed in order to identify the most predominantly used rhetorics in the visual images presentations in the cartoons depictions which cartoonists creatively manipulate to construct satire. More specifically, cognitive metaphor theory will be used to account how cartoonists employ cognitive aspect of metaphorical expressions through visual presentations to convey meanings with the aim of portraying political figures and issues of social and political magnitude to bring positive change in a society using visual metaphorical comparisons as weapons of creating and conveying satirical depictions.

The first section explores the political cartoons in relation to the growing research interest in the field of political cartoons studies in literature as a way of establishing relationshipbetween previous research andthis current study. Thesestudiesapproach political cartoons as a mediumwherebyvisualdevicesare utilized to reflect social practices as real-life referents of visual presentations. SeeEl Refaie (2009), for how readers interpret political cartoons. 
The second section analyzes how cartoonists employ visual metaphors in their cartoons depictions to construct social realities and representations of politicians and issues in society specifically in political cartoons published in Nigerian newspapers. Also, the data description and the method used have been outlined.

\section{The Cognitive Perspective of Metaphor}

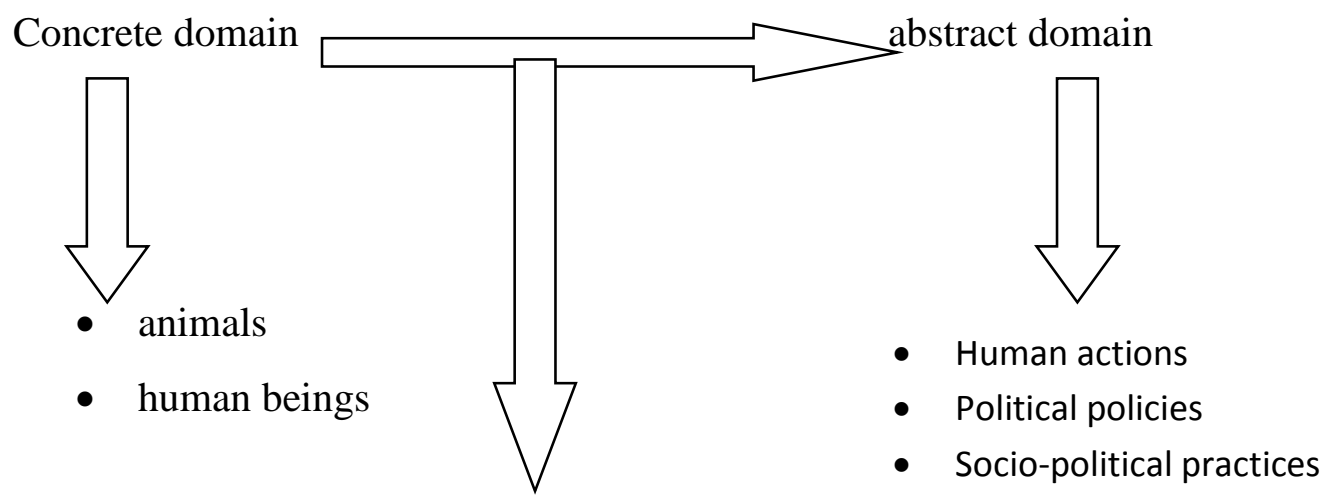

- visual metaphors

- metonymy

- Irony

- verbal elements

Figure1: illustrates the conceptual framework of metaphor.

Cognitive approach to metaphor was widely recognized and accepted in the 1980s through the contributions of Lakoff and Johnson in their work 'Metaphors We Live By'. The main claim made by Lakoff and Johnson, (1980) was that metaphorical language is pervasive and universal which is not arbitrary but remarkably systemic. Their argument was based on the fact that people's ordinary conceptual system is metaphorically structured helping them to comprehend complex or abstract experiences in terms of concrete concepts which they are more familiar with.From this perspective, cognitive metaphor is the term used to refer to the understanding of a particular idea that is the conceptual domain in terms of concrete or real experience. Thus, metaphor 
has been described as a mental process of "understanding one conceptual domain in terms of another conceptual domain" (Kovecses, 2002 p.4). The conceptual domain is the coherent organization of knowledge and experiences in human mind. For instance, life is understood as a journey. Similarly, these sets of mapping between a more concrete or physical source domain and a more abstract or target domain form the cognitive perspective of metaphor (Kovecses, 2002).The underlyingconceptualization of metaphor shapes and outline the way people look at things and how they think and act; and this enhance effective communication.

Taking into account the nature of cartoons' depictions, the cognitive model of metaphor is operationalized to construct realities through metaphors by connecting fictional portrayals of people and events into factual realities that reflect social practices in society. Thus metaphors are employed to effectively communicate societal issues and events to the public. Through their depictions, cartoonist creatively utilize cognitive process as a means of enhancing better understanding of the messages related to societal issues realistically.

More specifically, visual metaphors are the most frequent forms of metaphors that are used in the pictorial representations of Nigerian political cartoons. Visual metaphor refers to the way a particular event, person or place is represented in a visual image that indicates a kind of association to a particular thing through resemblance or similarity (Kaplan, 2005). Therefore, it is a kind of metaphor in which something or idea is portrayed visually as a target and compared to another thing that entirely belongs to another category as the source. In other words, the association is visually mappedfrom the source to the target. Thus visual metaphor is seen as a visual fusion of elements from two different areas into one single entity (Carroll, 1996). However, El Refaie (2003) challenged this view that visual metaphors are not based on visual fusion, but on more implicit form. He further stated that "most visual metaphors do not comprise fusion of two different elements into one due to the fact that the actual referent is not explicitly stated at all” (El Refaie, 2003, p.79). However, the verbal elements 
incorporated in the cartoon texts complement metaphorical representations of politicians, parties and specific groups.

Thus a range of deviceslike cognitive metaphor, visual metaphor, metonymy and irony are used to create satire in the form of cartoons in order to describe characters and processes of political and social culture (Edwards, and Ware, 2005). Among these uses of metaphor as in the case of Nigerian political cartoons, visual metaphor appears to be the most predominant device used for the construction of political satire to reflect the Nigerian climate. Due to their visual power, visual metaphors are often used in diverse genres in media such as political cartoons, advertising and films (Townsend, 2008). Therefore, cartoonists use visual metaphor as a device for encouraging insights and creating impressions to the public in order to influence their public opinion.

\section{Satire and Political Cartoons}

Political cartoons as Townsend (2008) describes are form of satire which enables the public to interpret political life in a particular society. Satire refers to the use of ingenious humor particularly irony, sarcasm and ridicule to criticize individuals' faults and behaviors (Encarta Dictionaries, 2009). Similarly, satire is described as a wicked weapon that features in political cartoons. It has also been described by Feinberg (1967) as "a playful distortion of reality". Originally, satire was a kind of literary art especially poetry meant for transforming society. Dryden (1974, p. 77) described satire as "poetry created for the purging of minds whereby human vices, ignorance, errors and all other things besides are reprehended". This traditional description of satire is quite realistic in our societies; it also applies to the cartoons whereby it is used in critical humor form to entertain, inform and reorient the audiences and at the same time expose the vices of politicians and prominent personalities play fully and artfully in societies.

More specifically, the main concern of satire in Nigerian perspective is often geared towards abolishing corruption, duplicity and rigidity of social, religious and political 
institutions and their practices (Akande, 2002). One thing important about satirists is their in-depth knowledge about their society as well as its different institutions; as such they don't usually attack blindly. Thus, to become a real satirist, one needs to be relatively secure about his position and knowledge of political institution he is satirizing. Therefore, satirists usually launch their attack decisively and precisely because they are intimately familiar with the conventions needed for succinct satirical attacks; as such, they are so ingenious in the art for the fact that they normally hit where it hurts. As satirists on the other side, cartoonists also skillfully manage to demonstrate an in-depth knowledge not only in political cartoons, but also the history of events leading to the current crises or issues under attack without necessarily exposing himself vulnerably to complete hatred.

Taking into account their nature, characteristic and function, political cartoons are very satirical messages and as such they are regarded as means for social and political reformation usually relayed through simple graphic illustrations. As satirical illustration therefore, political cartoons are strongly influential in the sense that they are most dreaded by government officials and politicians who are usually thebutts of the cartoons, for the great impact and power they are assumed to posses (Robinson, 1981). In addition, to achieve such impact, different visual devices are put into play such as visual metaphor, humor, satire and exaggeration among many which are employed by political cartoonists. Among these rhetorics, visual metaphor stands to be the most predominantdevice that Nigerian cartoonists harness to represent salient characteristics of politicians, parties and groups because visual metaphor speaks elaborately in such a way that it reveals humorous and most scathing critical evaluation of politicians.

Above all, political cartoons like other satirical arts have been used always as great weapons for offensive and deliberate attacks on eminent personalitiesprecisely political leaders to make them feel offended most. This is the reason why most influential political figures fear political cartoons and become watchful towards them. Evidently, the political cartoon genre is not only regarded as a weapon, but also an influential 
medium harnessed specifically to evaluate policies and political dispensation of a society and to do away with bad policies and practices through its critical, satirical and humorous offensive attacks on political leaders who are fully responsible for such ill policies for the betterment of the people and the society. Satire is mainly employed in cartoons as an armory of attack, due to its militant effect. Northrop Frye (cited in Test, 1981) has addressed satire as "militant irony". This means that satire inhibits aggression and the cartoonist utilizes this aggression by transforming it into a social and artistic expression for the purpose of satisfying readers' needs for play and humor. To this effect, political cartoons provide audiences the pleasure of superiority and safe release of aggression. Furthermore, through its imaginative power, political cartoons entertain and please audiences. The pleasure is usually derived through direct comparison between the real life events and the pretended ones in the graphic illustrations. Like other verbal and graphic devices, political cartoons exploit the ability of irony to unravel, ridicule and attack playfully, wittily, profoundly and artfully (Test, 1981). Therefore, cartoon satire is primarily used to criticize government officials and political leaders at a time of political turmoil, where verbal expression could hardly be done for the fear of libel, harassment and press censorship. Subsequently, using satire, political cartoons seek to point out the faults in the society and enable audiences to visualize solutions to such faults for the betterment of people and society.

\section{Political Cartoons in Nigerian Context}

The antecedent of political cartoons in Nigerian media is scanty and quite limited. The existing literature concerning the history of cartooning in Nigeria dates back to the late 1940 s to early 1950 s when they were regarded to be the significant contributors to the development of Nigerian media, particularly the newspapers (Duyile, 1987). Going by history, the West African Pilot and the Daily Times were believed to be among the first newspapers in Nigeria to publish cartoon strips and political cartoons (Duyile, 1987). In another development in Nigeria media history, Punch newspaper was first published in Match 18, 1973 and recorded tremendous success in the increase of its circulation which was attributed to the publication of the daily satirical cartoons focusing on social 
and political occurrences in Nigeria (Duyile, 1987). This made Punch to begin an evening edition in 1986 whereby a strategic position was specially allotted to its political cartoons on the front page (Duyile, 1987). In one of the surveys conducted, the result showed that about two-thirds of the readers identified political cartoons as one of their reasons for purchasing newspapers (Duyile, 1987). This development contributed immensely to the framework of many Nigerian newspapers and magazines today and put cartoonists on the prominent position to become social and political critics (Gbenro, 1985). Consequently, cartoon has become a distinctive and permanent feature of today's modern journalism in Nigeria. Basically, there is a need for conducting more research on Nigerian political cartoons due to their significant impact in the society, considering the paucity of research in the area. Similarly, only a few references can be found on the Nigerian political cartoons, despite the fact that they are regarded as an important medium of communication that has greatly contributed to the political commentary of Nigeria.

In terms of how they operate, Nigerian political cartoons are described as "traditions" which refers to the conventions and narrative characteristic that reflect the indigenous Nigerian culture as part of African political cartoons. The tradition involves use of legends, customs, rituals, creative use of traditional proverbs, vernacular language and Pidgin English. This provides imaginative reflection and expression of the national culture and politics. Another feature of these cartoons is that they are dynamic rather than static and as such they are easily mixed with the new tradition and the old in form of blending. In addition, its recurrent unique depictions makes it politically revealing by portraying the real life situation of political figures in a powerful presentation that really reflects the country's political arena.

\section{Methodology}

This study aims at examining how visual metaphor is creatively employed in Nigerian political cartoons as a vehicle of constructing political satire in the Nigerian sociopolitical context. In order to address this issue, total samplesof 105 cartoons which 
have been published in two most prominent and widely read Nigerian newspapers have been extracted.The cartoons are publishedon daily basis usually on the editorial pages and widely circulated across the country. These two newspapers are privately owned by Daily Trust and vanguard newspapers publishing companies. The newspapers were selected because they consistently feature political cartoons in each of their editions and explicitly provide political commentary in Nigeria. Thus, only cartoons from these two newspapers were included in the sample. Given the huge number of newspapers editions, convenience sampling was used to select the appropriate cartoons. Hence, there was no attempt to chronologically search newspaper archives for determining the sample. Nevertheless, the mass circulation and readership of the sampled newspapers and the number of cartoons indicated the sample generally represents cartoons published in major Nigerian newspapers. The samples of the cartoons were taken from 20 November 2009 to 24 May 2010. It was during this period that political tension in Nigeria was high as a result of power struggle following the protracted illness of the president that led to his death on 5 May 2010. Also, political controversy grew high in the country during this period. Therefore, the cartoons vividly depict and communicate crucial messages about current socio-political scenarios, events, issues and challenges facing Nigeria as a nation.

\section{Analysis}

In order to address how visual metaphors are predominantly used in different forms in Nigerian political cartoons to construct satire as a vehicle through which cartoonists communicate social and political messages reflecting the Nigerian political climate, the cartoons were grouped according to their tones and contents and subsequently analyzed based on their underlying metaphorical conceptualization. To this effect, two categories that are more pertinent to this study were taken from Manning and Phiddian's (2004) four categories for determining satirical tones of cartoons to examine how visual metaphors were used to portray salient characteristics of politicians, parties, groups and socio-political events in the Nigerian context. The results indicate that most of Nigerian political cartoons fall into these two categories. 
Category (1) Laughing Satirical Tone (LST) which is a concept that refers to a specific tone meant for constructing satire in the cartoons. As the concept implies, it stands for a tone that indicate humorous and ridiculous attacks on individuals to satirize their follies.Based on their depictions, Cartoons belonging to this category are characterized with reformative tone, calling urgent reforms on the political system and urging the politicians to correct and modify their practices. Press (1981) contends that most cartoons fit into this category. Category (2)Savage IndignationTone (SIT) which refers to a critical and exaggerated tone used in making severe attacks on political leaders to address sensitive and crucial issues in society. The tone of cartoons under this categoryreveals urgent attention and concern on sensitive issues. Cartoonists through the depictions express their fear on crucial issues affecting the public such as distribution of wealth, power sharingas well as the urgent need to do something on the issues at hand.

\section{Findings}

Due to the exploratory nature of this study, the cartoons were solely explored to sort out the emergent themes based on the contents of the cartoons. Thus, we developed these categories by inferentially studying the cartoons in order to unravel emergent themes. These categories include:

- Policy. This category portrayed images of the controversy over zoning policy which is the ruling party policy of rotating power among the geo-political zones of the country. The cartoons depicted the current political tension that emerged as a result of the demise of the late president who came from the northern part of the country, before the end of his first term.

- Incumbency factor. This category depicted images that portrayed a new political trend in Nigerian politics. The depictions usually comment on current politicalissues such as power politics. 
- Corruption.This category depicted corrupt practices in public services, and the political parties. The depictions are satirical, lampooning politicians and political parties to reform the corrupt social practices.

- Public Responses. This category portrayed both politicians including opposition parties and the public as well as other responses that emerged as a result of current issues and political situation of the country. Through responses, people's common voice or opinion is represented and expressed.

Taking into account the qualitative nature of this study, it was quite essential to establish inter-rater agreement which is a means of increasingreliability of findings (Meadows, \& Morse 2001). To this effect, a Nigerian graduate student who was quite familiar with Nigerian political cartoons was groomed about conventions of the cartoons and employed to participate as a co-rater for sorting out emergent themes based on the established categories. Hence, we coded the cartoons and deliberated on the consistency of the coding which was around 80 per cent. However, due to the nature of cartoons, categorizing them rigidly is almost impossible because they are subject to different interpretations (Manning \& Phadian, 2004). We resolved our disagreements on the cartoons had been given different codes.In terms of cartoon content, we independently coded themes and later met and discussed about emergent themes. Table 1 contains the description of the results.

Table 1:Results

\begin{tabular}{|l|llll|l|}
\hline Tones & \multicolumn{3}{|c|}{ Themes } & \\
\hline Laughing & Policy & Incumbency factor & Corruption & Responses & Total \\
satirical & 20 & 19 & 14 & 12 & 65 \\
Savage & 10 & 12 & 13 & 5 & 40 \\
indignation & & & & & \\
& & & & \\
\end{tabular}

Table 1 shows the distribution of the cartoons. The cartoons studied $(\mathrm{N}=105)$ were distributed between a tone of laughing satirical $(n=65)$ and savage indignation $(n=40)$. 
Laughing satirical cartoons are more frequent due to their corrective tone. They represented 62 per cent of the cartoons. They also carry satirical effects through ingenious humor than savage indignation which represented 38 per cent of the samples. Thus political cartoons rely more on laughing satirical cartoons in constructing satire because humor carries more weight in its effect.

From laughing satirical category, two themes emerged: policy, $(n=20)$ and incumbency, $(n=19)$. While savage Indignation comprised the other two themes: Corruption and Responses. Cartoons in zoning depicted Nigerian president in a continuous struggle to dismantle zoning which is their party's policythat stands as a barrier to his ambition to contest for presidential election in 2011. This is a current contention and debatable issue in Nigerian politics. Figure 1 illustrates the issue

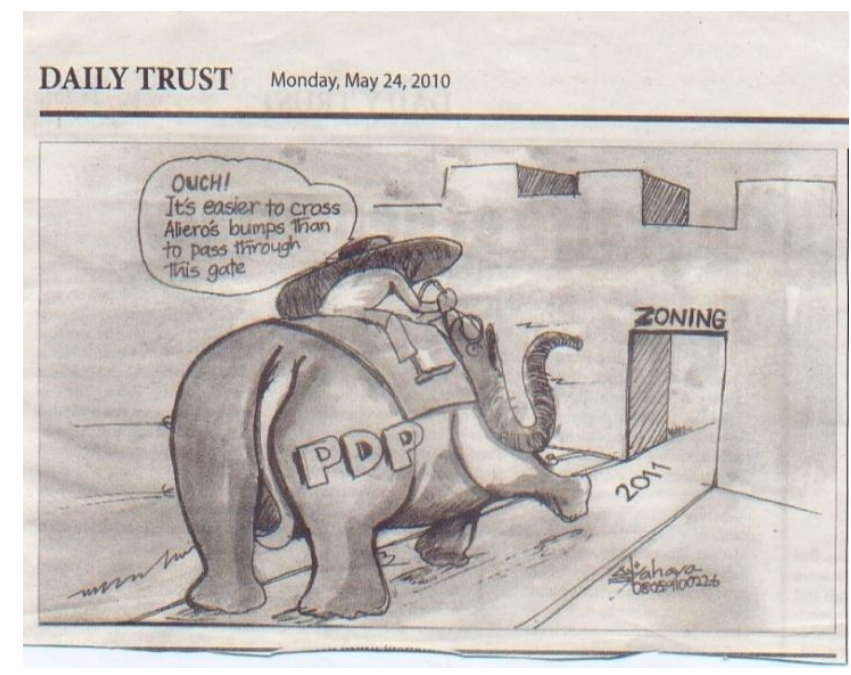

Figure 2:Illustrating Zoning Policy in Nigerian Politics

In this cartoon, the pictorial image of an elephant denotatively refers to the ruling party, PDP whose motto is 'power' as the Africa's biggest and most powerful party. Nigerian president, Goodluck Jonathan was portrayed in a race to 2011 elections galloping on the giant animal towards a solidly built fortress with small entrance. The fortress refers to 'Aso Rock' or presidential villa, the official residence of Nigeria's president and the small entrance refers to zoning which stands against the ambition of the president to 
contest because it is not his turn. The underlying metaphorical thought of the depiction can be expressed as: 'Elephant is powerful'. The connotative expression is that dominance is achieved and sustained through power; and that power has its limit; the writtencaptionmetaphorically buttresses the limit of the President. In other words, the possibility of the president to qualify as the ruling party's presidential candidate in the forthcoming coming elections in Nigeria is just like the possibility of the elephant to pass through the fortress.

From the depiction, visual devices including humor and irony were fused together to form a strong visual metaphor of animal to critically satirize the president who was satirically portrayed as someone who is wild and desperate for power at all cost.The depiction represented not only the nature of Nigerian leaders, but also typical African leaders. For more illustrations on how African leaders abuse power, see (Eko, 2007). It was presented in such a way that it highlights on the current issue that dominates political debate prior to general elections.

As a way of power continuity and sustainability and bearing in mind the multi-ethnic nature of Nigeria, the ruling party came up with zoning agenda to ensure that power is shifted to two main geo-political zones, south and north at two terms tenure. Zoning crises emerged as a result of the demise of the late president who came from the north towards the end of his first term tenure. This gave mandate to the vice president who came from the south to become president according to the constitutional demand to the end of the first tenure. However, the next presidential candidate in the party is expected to emerge from the north to complete the second tenure before the mantle of power shifts to the south. Obviously, this agreement has exempted Goodluck Jonathan to contest at the forthcoming elections but he insists to contest by all means.Figure 2 also focuses on the same theme. 


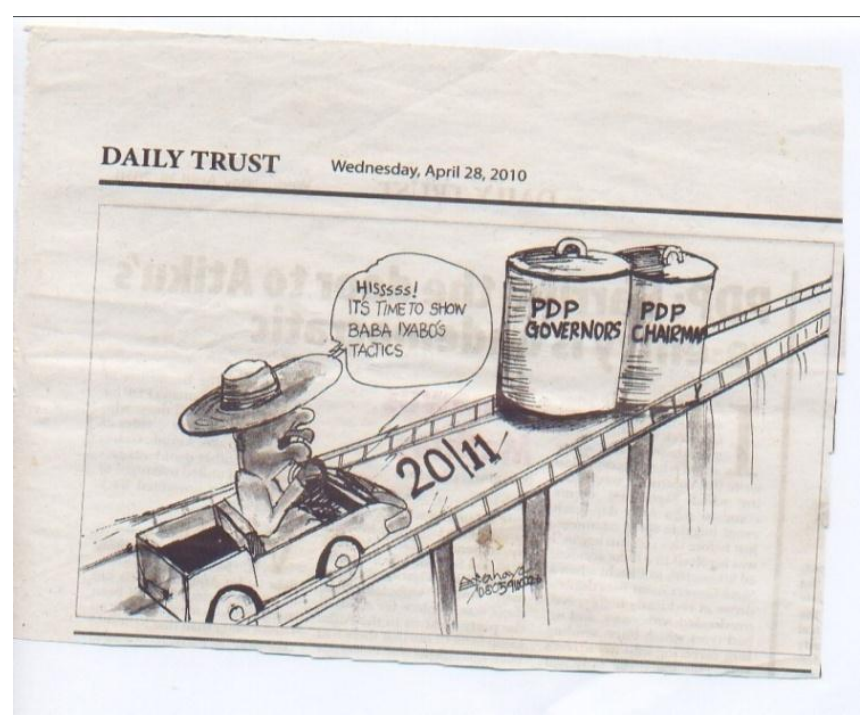

Figure 3:Illustrates Incumbency Factor in Nigerian Political Climate

Figure three is another example of laughing satirical category. The depictionsatirically portrayed the Nigerian president on a bridge driving a car straight towards two big tanks bearing bold inscriptions 'PDP GOVERNORS' and 'PDP CHAIRMAN', on his way to 2011 general elections. The metaphorical underlying of the depiction readsas: 'Politics is a journey', derived from the conceptual metaphorical expression: 'Life is a journey'. The verbal and visual elements in the depiction portrays connotatively the herculean task ahead of the presidentto secure his party's ticket as its presidential candidate due to zoning dilemma he is currently facing as his major obstacle for contesting in the forthcoming elections. The PDP governors and its Chairman were depicted as alpha and omega in decision making and the whole affairs of the party. They are regarded as remote controls and the most influential members of the party who plan and execute its decisions. The visual depictions portrayed some of the tactics that Goodluck Jonathan is likely to playlike his predecessor, President Obasanjo popularly referred to as Baba Iyabo in the media, who exploited the governors and party chairman to execute his selfish plans. The party chairman and its governors will be forced to pave way for the president to contest for the elections as their only options to retain their positions or to contest for the second tenure upon which failure to do that 
is to forfeit their positions. Metaphorically, the written caption or verbal text provides details of the political situation which is the new trend in Nigerian politics.

Figure 3 also belongs to laughing satirical category. The topic of the depiction focused on new trends in politics upon which political leaders choose candidates of their choice and impose them on people as their successors at the end of their tenure. This is another form of powerpolitics or power continuity which is so pervasive in Nigerian politics. Political leaders particularly President and State governors are solely responsible for this new trend as illustrated below

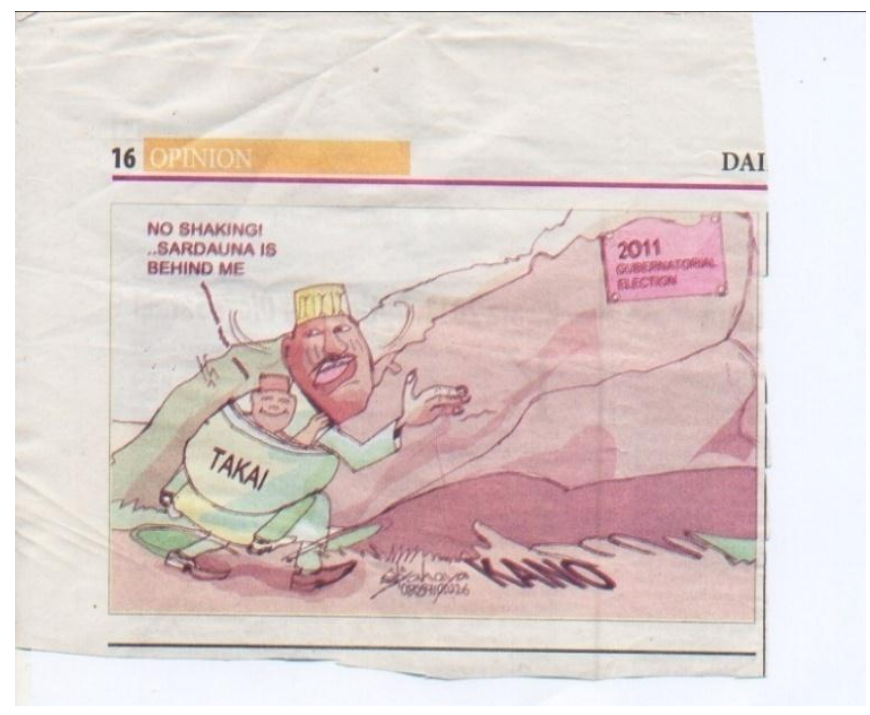

Figure 4: Illustrates Power Politics

This figure denotatively refers to the then Kano State governor, who was ridiculously satirized carrying his chosen candidate in a backrest position as the most eligible candidate for the gubernatorial elections in the forthcoming 2011 general elections. The cartoon illustrated beyond doubt the governor's utmost support to his candidate. The depiction also portrayed the supremacy of the adopted candidate over other candidates as the most eligible one. This also reveals the new and current trend in Nigerian politics, where people's mandate is not what matters in determining political candidature in Nigeria unlike other real democratic countries. 
The underlying visual device is metonymy which is a kind of metaphor expressing part to whole relation; the governor represents the entirepeople of his state. The main metaphor is related to "life is a journey metaphor" like the previous one. The road map was clearly shown in the depiction and the destination was also indicated with boldly written inscription '2011 GUBERNATORIAL ELECTION' on a signpost. The verbal text or the written caption was metonymically expressed indicating that the one with governor's support is the one with majority even if people are not in support of him.The word Sardauna refers to the governor's traditional title. In a nut shell, the depiction connotatively implies that political leaders in Nigeria use their offices, positions and influence to impose candidates on people to contest at almost all levels of power in Nigeria. These depictions are some examples of the laughing satirical cartoons used to communicate messages in order to transform people, political and social practices in society. The following figures focused on savage indignation category.

Unlike the laughing satirical, savage indignation category are used to show the cartoonists' fear, and desire to call for the attention and concern of the public over crucial issues such as the distribution of wealth and power (Manning and Phiddian, 2004). Figure 4 was a good example of this category. Corruption has become highly endemic in almost every sector in Nigeria. It is one of the contributing factors that hinder Nigeria's economic advancement. Thus, political cartoons are used as a means of satirizing politicians savagely to transform them and their follies for the betterment of society. Figure 4 illustrated such depictions of politicians. 


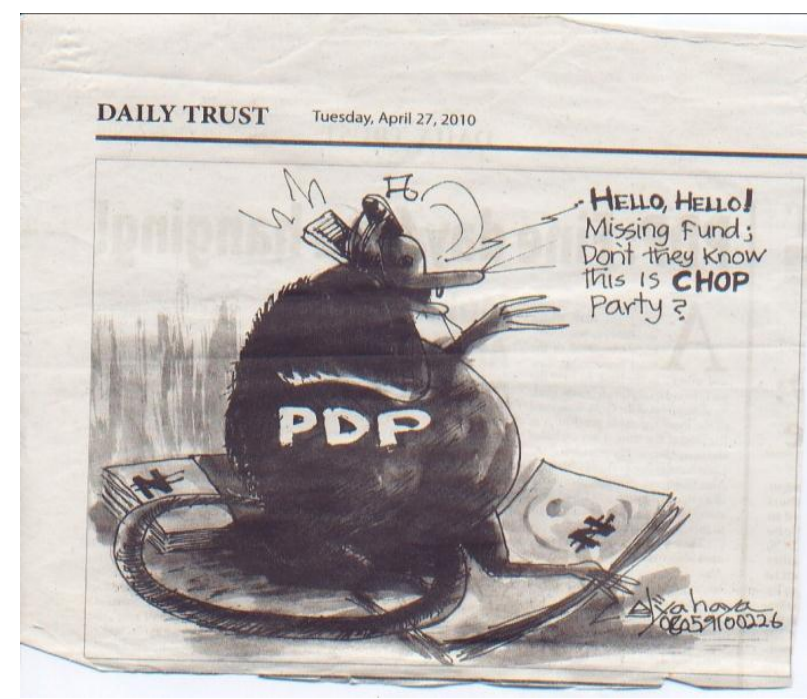

Figure 5:Illustrates Corruption in Nigerian Politics

The theme of this depiction was corruption. In this political cartoon (fig.4), the cartoonist denotatively depicted Nigeria's ruling party, Peoples Democratic Party (PDP) as a huge rat comfortably seated in between two bulky bundles of Nigeria's currency, grasping one bundle superciliously while resting its tail on the other and at the same time making a phone call. Visual metaphor was employed to represent the party and the party members or the political leaders. In this visual metaphorical representation, animal metaphorthat can easily be understood by the audiences was used. The underlying metaphorical expression is: 'Rat is a thief'.

Metaphorically, both the verbal and visual elements of the text revealed how the political leaders of the ruling party mysteriously squander public fund and resources subjecting the citizens to abject poverty despite the country's vast natural and human resources. The depiction connotatively signifies that politicians in Nigeria especially the ruling party who solely formed the current government are extremely corrupt. They exploit the party as a conduit for siphoning the country's resources through illegitimate means. The cartoon portrayed corruption, mismanagement and public looting as big impediments which pose serious challenges to Nigeria's struggle for social, political and economic development. Due to the enormity of the problem, and the fraudulent 
character of most Nigerian politicians, the cartoonist savagely satirized politicians to the extent that they were dehumanized and reduced disdainfully to the status of low and deceitful animals.

Finally, figure 5 focused on the response of the public including political leaders on serious challenges related to poor infrastructures in Nigeria, especiallypower failure. The situation is so paradoxical in the sense that Nigeria is one of the world's richest petroleum producing countries, but political leaders succeeded in plunging the country into darkness.

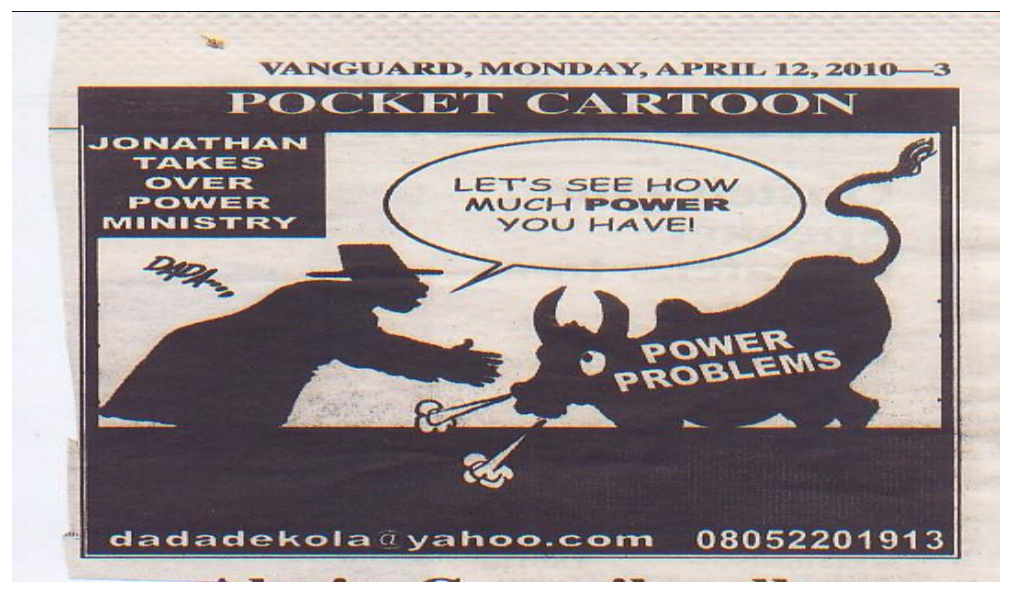

Figure 6:Illustrates Poor Infrastructure in Nigeria

In this cartoon, the 'signified was the president, who was depicted in a kind of posture with open hands showing his readiness to engage into a combat with a giant bull that bore bold inscription 'POWER PROBLEMS'. Acute shortage of electricity supply has crippled Nigeria's industrial developments. Previous administrations have failed to provide sufficient electricity supply to the country. The depiction thus portrayed the president satirically in a bull-like shape so as to fit into the real combat. Although the cartoon was from other newspaper (Vanguard), the same visual device was employed to facilitate easy understanding of the message from the audiences.Like other cartoons, the metaphorical underlying concept of the depiction might be expressed as: 'Facing a bull is a strenuous task'. This expression is quite similar to the common figurative 
expression: 'Taking the bull by the horn'. The cartoon connotatively the fusion of the verbal and visual elements reflected the president's declaration to oversee the affairs of power ministry himself. This signifies that power problem has almost reached a stage beyond the ministerial control and demands urgent intervention. Moreover, the written caption precisely showed the problem is so enormous that the president's effort to tackle it at initial stage seemed to be a trial.

Thus, we have seen how Nigerian political cartoonists creatively exploit visual and verbal metaphors to construct political satire in order to communicate persuasive messages. Likewise, political cartoons rely heavily on the visual and verbal devices to make impact.

\section{Conclusion}

So far, this study has provided us with additional insights on how visual devices are manipulated to construct a form of political satire, in Nigerian political cartoon genre. The genre contributes to political debates and commentary aimed at promoting political orientation and awareness in Nigeria. More specifically, the studyexplored the power of visual metaphor in the construction of satire in Nigerian political cartoons published in two most widely read Nigerian newspapers in 2010.Using the perspective of cognitive metaphor, the cartoonists manipulate visual devices especially visual metaphor which has been identified as the most predominant device to construct satirical depictions which facilitate audiences' better understanding of issues of national interest reflecting social realities aimed at bringing positive change in the Nigerian socio-political context.These newspapers use cartoons as an avenue for illustrating current social and political issues in their efforts of social and political reformation.

Political cartoons rely heavily on satire created and conveyed mostly visually for making constructive criticisms on politicians, public officers, political and social practices. Despite the increasing use of the cartoons in Nigeria especially the printed 
media, there has been little research on political cartoons. Previous studies have focused on visual rhetorics (Carroll, 1996); Understanding visual metaphors (El Refaie, 2003); Political cartoon readership in Nigeria (Udoakah, 2006). Yet, no existing research that has investigated on visual devices used for constructing satire being it a vehicle for cartoon's depictions that communicate persuasive messages of public interest, hence the rationale for conducting this current study. The study suggests that visual metaphor is a powerful rhetoric which can be creatively utilized to provide a better means of communicating important messages because it strongly appeals to the mind of the readers more precisely and succinctly than verbal expressions.

We have shown that the presentation of verbal and visual metaphors in Nigerian political cartoons indicate tones. From the summary of results in table I, indicate that the predominant tone of the cartoons fall under the laughing satirical tones having the higher percentage as 62\%. This shows that Nigerian political cartoons are mostly aimed at reforming politicians and political practices in Nigeria. Through their depictions on current social and political issues and events, political cartoons contribute immensely to political commentary.

The findings of the study indicate that the mutual effectsof verbal and visual devices in the cartoons provides a convenient way of using language specifically to accomplish communicative purposes in a society.Finally, the study was not aimed at determining the opinion of audiences on the impact of the cartoons. Nevertheless, the paucity of research on political cartoons in Nigeria despite their increasing use, calls for further research in the area. Therefore, we suggest that further research should be conducted on the impact of political cartoons on public opinion in Nigeria. Future should also explore the communicative functions of political cartoons as communicative artifacts. 


\section{References}

Akande, O. (2002). A Semiotic Analysis of Political Cartoons: A case study of Nigeria., University of Oklahoma, Oklahoma.

Conners, L. J. (2005). Visual Representations of the 2004 Presidential Campaign: political cartoons and Popular Culture References. American Behavioral Scientist, 49 49(3), 487-497.

Duyile, D. (1987). Makers of Nigerian Press: An Historical Analysis of Newspaper Development, the Pioneer Heroes, the Modern Press Barons and the New Publishers from 1859-1987: Gong Communications.

Edwards, J., \& Ware, L. (2005). Representing the Public in Campaign Media. American Behavioral Scientist, 49(3), 466.

Eko, L. (2007). It's a Political Jungle Out There. International Communication Gazette, 69(3), 219.

Elkins, J. (2003). Visual studies: A skeptical introduction: Psychology Press.

El Refaie, E. (2003). Understanding visual metaphor: the example of newspaper cartoons. Visual Communication, 2(1), 75.

El Refaie, E. (2009). Multiliteracies: how readers interpret political cartoons. Visual Communication, 8(2), 181.

El Refaie, E., \& Horschelmann, K. (2010). Young people's readings of a political cartoon and the concept of multimodal literacy. Discourse: Studies in the Cultural Politics of Education, 31(2), 195-207.

Feinberg, L. (1967). Introduction to satire: Iowa State University Press.

Gbenro, B. (1985). National concord, Sunday concord: selected editorial cartoons from Boye Gbenro's portfolio: first series, 1985: Concord Press of Nigeria.

Kaplan, J. (2005). AN EARNEST FOR OUR TIME KAOS, Handbag and Lady Bracknell's Confinement. Irish Studies Review, 13(3).

Kövecses , Z.(2002) Metaphor: A Practical Introduction.: Oxford University Press, New York.

Lakoff, G., \& Johnson, M. (1980). Metaphors we live by (Vol. 111): Chicago London. 
Manning, H., \& Phiddian, R. (2004). In defence of the political cartoonists' licence to mock. Australian Review of Public Affairs, 5(1), 25-42.

Press, C. (1981). The political cartoon: Fairleigh Dickinson University Press.

Robinson, J. (1981). The 1970s, best political cartoons of the decade: McGraw-Hill Companies.

Test, G. (1991). Satire: spirit and art: University of South Florida Press (Tampa).

Townsend, K., McDonald, P., \& Esders, L. (2008). How political, satirical cartoons illustrated Australia's WorkChoices debate. Australian Review of Public Affairs, 9(1), 1-26. 